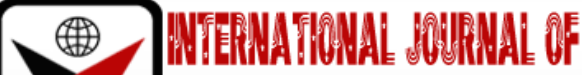 \\ בmRक
}

ISSN 2278-0211 (Online)

\section{Using the Syllabic Method to Enhance the Reading Skills of Basic Six Pupils of Yorogo Primary School in the Bolgatanga Municipality of Ghana}

\author{
Alaric Awingura Alagbela \\ Lecturer, Department of School of Science, Mathematics and Technology Education, \\ C. K. Tedam University of Technology and Applied Sciences, Ghana
}

\begin{abstract}
:
One main objective of educating children is to make them literate. The ability of the child to read is thus fundamental to the child's literacy development. Therefore, this study sought to investigate the extent to which the syllabic method of teaching reading could be a panacea to the reading challenges of basic six pupils of the targetedschool. Action research design was employed in this study by first engaging in a pre-test exercise followed by the intervention activities and a post - test activity. The purposive sampling technique was applied in the sampling process. To this end, thirty (30) pupils and three (3) classroom teachers at the upper primary making a sample size of thirty-three (33) constituted the unit of analysis. Test and an interview guide were the tools used in gathering data from the pupils and teachers respectively. The dependent $t$ - test was utilised in the determination of significant difference relating to the pre- test and post- test results after the intervention. Per the findings and conclusions arising out of the study, the recommendations are that, managers of education in the district should organize training workshops for basic school teachers in the appropriate use of the syllabic method and other alternative methods so as to enable the said teachers effectively sharpen the reading skills of their pupils. Furthermore, teachers should during teaching and learning, be more eclectic in the use of the various methods of teaching reading in order to arouse the interest of learners in the process.
\end{abstract}

Keywords: Syllabic method, reading skills, pupils, intervention

\section{Introduction}

\subsection{Background to the Study}

English is one of the major subjects learnt in schools across the globe. It is considered an international language (Jumba, 2016). Aside it being an international language, it is the official language of Ghana and almost every content of most of the subjects studied in Ghanaian schools are written in English. Again, English is used as a medium of instruction in Ghana. It is therefore imperative that recipients of formal education take the learning of English language seriously, both inside and outside classrooms. Due to the central role of English in the Ghanaian education system, successive governments have provided support including educational materials to support the teaching and learning of the English language. This requires that in an English Language classroom, the teaching and learning process should be effective in order that lasting learning can occur.

One important aspect of the English Language syllabus in basic schools is reading. The acquisition of reading skills is very important in the life of every child and in one's adult life. According to Duff, Hayiou-Thomas and Hulme (2011), children will be inadequate if they do not acquire reading skills. They further assert that, children who read proficiently generally do better in the various subject areas including mathematics and science.Parris, Gambrell and Schleicher (2008) argue that the capacity to read is the primary need for full participation in one's society and economy. However, developing the skills to read happily is not a simple process. Katanga (2005) asserts that, the common problem associated with the teaching and learning of language that is making it difficult for pupils to identify words so as to pronounce the words correctly are due to the wrong methods of teaching and inadequate use of teaching and learning materials (TLMs) by some teachers.

According to Lerner (2006), a number of learners are unable to use reading as a tool for learning, getting new information, ideas, attitudes and values from standard four upwards. Only $26 \%$ of pupils who reach 6 th and final year of Primary School are literate in English Language (Ministry of Education, Ghana 2008, and 2007 Educational Assessment Report) cited in Leherr (2009). This has implications on the performance of the pupils. At the basic level, Primary Six (6) serves as a transitional class between the Primary and Junior High School. If pupils are not helped at this early stage to build a firm foundation in their literacy abilities, they will find it extremely difficult if not impossible to achieve their 
academic dreams because the success in education appears to have a strong association with a person's English Language proficiency, especially in an English-speaking country such as Ghana. It is in the light of this necessity that this study sought to use the syllabic method to help improve the reading skills of class six pupils of Yorogo Primary School in the Bolgatanga Municipality in the Upper East Region of Ghana.

\subsection{Purpose of the Study}

The purpose of this study was to investigate the extent to which the use of the syllabic method improves the reading skills of primary six pupils in Yorogo Primary School. Specifically, the study focused on extent to which the syllabic reading method improves the reading skills of pupils. It also investigated the challenges relative to the use of the syllabic method in teaching reading. Finally, the study sought the solutions to the challenges in using the syllabic method.

\subsection{Research Questions}

The following research questions guided the study;

- To what extent does the use of the syllabic method improve the reading skills of primary six pupils of Yorogo Primary School?

- What are the challenges that teachers encounter in the use of the syllabic method in teaching reading?

- What are the solutions to the challenges that teachers encounter in the use of the syllabic method in teaching reading?

\section{Literature Review}

\subsection{The Concept of Reading}

According to Rockets (2011), reading is a multifaceted process involving word recognition, comprehension, fluency and motivation. Reading also means making meaning from print. In addition, reading is also about decoding, comprehension, narrative, familiarity with books and other printed material and a culture of wanting to and enjoying reading (House of Commons, 2004). This goes hand in hand with Derchant (1993) who stated that reading involves the recording of the printed words in the brain by the visual and perceptual processes, converting the written symbols into language and through cognitive and comprehension processes creating meaning by relating the symbols to the readers' prior knowledge. Moreover, Harris (2006) stated that reading could be defined as the understanding of the written text. This simply means that the end result of any act of engagement should be comprehension of a text. She emphasized four principles of effective readers. These are: effective readers do a lot of predicting; effective readers use certain strategies to help them with reading difficulties and blockages including sounding out letters in words and breaking words into parts; effective readers draw heavily on their background knowledge including past experience with reading, knowledge of sounds and words, most importantly knowledge about the content being written in the text; and effective readers are typically confident enough to read difficult text.

Reading is an interaction process that goes on between the reader and the text, resulting in comprehension. The text represents letters, words, sentences and paragraphs that encode meaning. The reader uses knowledge, skills and strategies to determine what that meaning is (Heidi, 1998). Psychologists tell us that although reading begins with our visual perception, it is our brain that interprets the shapes and patterns as letters and words (Nancy \& Keith, 2009).

Accordingly, the process of reading is not passive; words do not just jump from the page into our heads. Just like speaking and listening, we are actively involved in constructing meaning from these shapes. According to Ruddell and Singer (1994), a reading model tries to depict how an individual perceives a word, processes a clause and comprehends a text.

\subsection{The Relevance of Reading}

Reading is an essential tool to acquiring higher education. Pupils who are good readers areable to source information about themselves and their environment.In the view of 'Becoming a Nation of Readers'; The Report of the Commission on Reading(USA), states that reading is a basic life skill. The Commission explained that it is the cornerstone for achild's success in school and indeed, throughout life. It further states that, without theability to read well, opportunities for personal fulfillment and job success inevitably will be lost.

According to Beryl and Marcelle (2004), reading is one of the most beneficial pleasurable andrelaxing pastimes. They add that reading can never be replaced, even in this age oftechnology.In the view point of Ghana Education Service/Teacher Education Division (GES/TED,2004), pupils are able to gather information through reading. Reading also helps learnersto learn the other subjects in the school curriculum.

Charlotte (1967) stressed the importance of reading and proposed for the development of awell-organized program incorporating child's literature directly in the Elementary Schoolreading curriculum. Charlotte pointed out that children satisfy their desire for informationand intellectual stimulation through reading. In her view, pupils discover specific facts through reading and present them clearly and in a meaningful way.

Durell (1956) intimates the socio-cultural importance of reading to the child. Durell states that the child with limited interest in reading is a danger to the society. In our contemporary system of child upbringing, all children are expected to attend school and attempt to read.Society demands that the child should be a reader. A child, who cannot read risks insecurity,loses self-esteem and inability to pursue her interest to the fullest satisfaction.

Leland (1961) cited in Iris and Sidney (1967), state that literature and for that matter reading is entertainment. According to him entertainment is a noble end to education. Hecontends that unless children at school learn to love to 
read and enjoy reading for its ownsake as entertainment, we will be missing one of our wonderful citizenship opportunities. Hefurther opines that reading is a guidance resource. Reading makes it possible for a person toget insight into himself so that he can possibly change behaviour. Leland concluded his viewson the benefits of reading by pointing out that reading stimulates creative activities. Heexplained that reading serves as a springboard to creative activities. Creative reading ofliterature, coupled with a rich program in the other arts, gets one art to feed the other. Thericher the pupils' experiences in reading and dramatics, the richer they become in thecreative aspect of living.

Beryl and Marcelle (2004) summarize the benefits of reading as: it provides entertainment and enjoyment, provides information, extends the pupils vocabulary by exposing them to new words, stimulates the pupils' minds and keeps it active and finally, developspupils' comprehension skills.

\subsection{The Syllabic Method}

A syllable approach is characterized by the use of the syllable as the basic building block or unit for decoding words. Students learn syllables before reading words and texts. A syllabic method to teaching reading uses syllable recognition as the primary word attack skill (Ankrah, Nyanta and Opoku, 2017). It is thus a method of breaking words into syllabus. For instance, individual is broken as in-di-vi-dual. The word destination is broken asdes-ti-nation. According to Adam (2016), even though, this approach may slow down reading, it enables pupils develop word-attack skills and also helps pupils to read words on their own. The use of the syllable as a unit for initial acquisition of reading has always been advocated. It is argued that since English alphabetic writing is based on a mapping between sound-stream and symbol, adecoding approach is necessary at early stages of the acquisition process. However, conventional 'phonics' methods confound two very difficult tasks in initial learning:(1) acquiring the notion that the orthography tracks sound directly and meaning only indirectly; and(2) understanding that the alphabetic unit corresponds to the highly abstract phonological unit 'phoneme', which is both difficult to pronounce in isolation and difficult to recognize and 'blend'.

Syllabic bridge hypothesis', suggests that pre-readers could learn print-to-sound associations by syllable-size units (Doignon-Camus \&Zagar, 2009). This alternative hypothesis relies on speech primacy and takes the available syllable units as starting points of spelling-to-sound connections. In this case, the building of associations between letter clusters and syllables would be a direct and rapid way of learning the first spelling-to-sound correspondences. The syllabic bridge hypothesis relies on the phonological availability of syllables but also on their visual availability. At first sight, letter clusters that correspond to phonological syllables do not seem to be available orthographic units. The reason is that letter clusters that form syllables are completely embedded in printed words.

\subsection{Challenges in the use of the Syllabic Method}

A major problem of the use of the syllabic approach to teaching is that English has a complex syllable structure with consonant clusters both initially and terminally: thus there are some thousands of separate syllables to be learned. The point of the syllabary approach is to dissect the conceptual problems of alphabetic reading for the child rather than presenting all of them together as it is usually done.

Accomplished reading ability develops gradually through engagement in meaningful learning activity in which learners receive explicit instruction, guided and independent practice and assistance from teachers and more accomplished peers to support their transition to become independent self-regulatory readers (Iaquinta, 2006). If students do not reach a certain stage in their reading development they will need more extra support that teachers cannot provide during class time. In teaching reading, it is important to focus on the class sizes because the smaller the group the easier it becomes to teach reading. This explains that, large class size is one major problem that teachers face when using the syllabic method of teaching because the teacher may not get enough time to attend to the unique needs of all the students.

Every professional teacher needs to equip himself or herself with the knowledge of the developmental processes that go on in the child in order to understand him/her and handle their learning challenges adequately. According to Richards and Rodgers (1986), if a classroom teacher will be successful in whatever he/she teaches, he/she needs to know who his/her learners are. Knowing the learners involve taking into cognizance the developmental levels of the learners. Reading involves a mental process and has never been easy for beginner readers and even the advance readers. According to Snow, Burns and Griffin (1998), young beginner readers who must acquire oral and literacy skills in English simultaneously encounter a great deal of cognitive challenge. Birch (2002) believes that reading involves the use of cognitive knowledge and learning strategies as well as linguistic knowledge and processing strategies.

\section{Research Methodology}

\subsection{Research Design}

The research design that was adopted for the study is action research design. Carr and Kemmis (1986) describe action research as being about the improvement of practice, understanding of practice and the improvement of the situation in which the practice takes place. Action research provides the means by which professional people may increase the effectiveness of the work in which they are engaged (Mills, 2011). It is the collection and analysis of data to provide a solution to the practical, valued problems of educators within their own school or organization. This design was chosen because the problem under investigation demands putting in an intervention to enhance pupils' reading skills. Action research lends itself to the use of empirical figures to get feedback on the impact of the intervention that was put in place. Action research has some advantages that attract researchers. According to Dick (2002) an action research project can give researchers the opportunity to improve their own professional practice and ameliorate the situation investigated. 
Action research has some weaknesses. Given its engagement with problem solving in a particular context, questions can also be asked about the relevance of any findings beyond the immediate research setting. Thus, it lacks the potential of its findings being used to generalize in other areas. Rapoport (1970) also draws attention to the risk of the researcher becoming over-involved in the situation or of being used as a tool in organizational politics. This may be a particular difficulty for the insider action researcher who is simultaneously a researcher and organizational member. Susan, Spinks and Canhoto (2015) also opined that, action research puts the researcher in tension because he/ she plays a dual role as a change facilitator and a researcher. However, in the current circumstance, this study clearly lends itself to action research design hence its adoption.

\subsection{Population}

The target population for the study included all class six pupils in Yorogo Primary School in the Bolgatanga Municipality of the Upper East Region of Ghana. Again, some teachers in the school were selected for the study and interviewed and so they formed part of the population of the study.

\subsection{Sampling Procedure and Sample Size}

Purposive sampling was used to select thirty (30) pupils in the class who had difficulty in reading. Again, three (3) classroom teachers from the upper primary were included in the study to ascertain the challenges in the use of the syllabic method of teaching reading and how to deal with such challenges. Therefore, the sample size stood at thirty- three (33) respondents/participants.

\subsection{Research Instruments}

Two instruments were used to gather data for the study. They included test and interview. As said by Cronbach (1970), a test is a systematic procedure for observing and describing one or more characteristics of a person with the aid of a numerical system. The children were tested before the intervention and after the intervention. The classroom teacher was interviewed to ascertain the challenges that are encountered with respect to the use of the syllabic method of teaching reading and some suggested solutions to the challenges.

Interview connotes a one-on-one interactive process where an interviewer elicits the views and opinions of an interviewee orally about a concept. Interviews can either be structured, unstructured or semi-structured (Creswell, 2012). Accordingly, you ask open-ended questionsso that the participants can speak to their experiences unconstrained. Interviews in qualitative research have both advantages and disadvantages. Some advantages are that they provide useful information when the researcher cannot directly observe participants. Compared to the observation, the interviewer also has better control over the types of information received. This is because the interviewer can ask specific questions to elicit such information. It also helps to make clarifications to the participants especially if there is a misconception about a question. Finally, it can be administered to those who cannot read (Creswell, 2012). The disadvantages are that interviews provide only information 'filtered' through the views of the interviewers. Also, interview data may be deceptive. Again, the presence of the researcher may affect how the interviewee responds. Interviewee responses also may not be articulate, perceptive or clear. Interviews are difficult to conduct as they need a great deal of experience to handle emotional outburst.

Interview was selected because it enabled the researcher obtainin-depth information about the challenges the teacher faces in using the syllabic method in teaching reading.

\subsection{DataCollectionProcedure and Intervention Measures}

Permission was obtained from the head teacher before the data was gathered. All the participants were briefed about the purpose of the data collection exercise. They were also assured of the confidentiality of their responses and their anonymity. First, a test was conducted to ascertain the level of performance of pupils before the intervention. Afterwards, an intervention, using syllabic method, was put in place to help the pupils improve in their reading skills. During the intervention period, the following steps were followed;

- I wrote the word(s) on chalkboard example reseat, random, practice, bamboo, mathematics, butterfly, crocodile cupboard, porcupine, periwinkle, temperature, principal, consideration, postman, aeroplane, polygamy, Bolgatanga, photograph, advertisement, institution.

- I made each pupil try to pronounce the words one after the other

- I then broke the words into syllables. Example ma - the - ma - tics, mi - ni- mi -zes, po - ly - ga- my, af - ter noon, com - mer - cial, cal -cu - la - tor, Bol - ga - tanga, post -man, pe- ri - win- kle, but - ter - fly, com - pu ter, lap - top, ob - jec - tive, trans- por -ta- tion

- I then read the syllables for pupils to listen to.

- I read the word by blending the syllables of the words.

- I then practiced steps 3 to 5 with the pupils.

A post-test was conducted to determine whether the intervention really worked or not. The three classroom teacherswere finally interviewed to ascertain the challenges to the syllabic method in teaching reading in the classroom and some suggested solutions to the challenges.

\section{Results and Discussion}

- $\quad$ Research Question 1: To what extent will the use of the syllabic method improve the reading skills of primary six pupils of Yorogo Primary School in the Bolgatanga Municipality? 
This question was posed to enable the researcher find out whether the use of the syllabic method could help the pupils overcome their reading problems. To answer this question, the pre-test results are shown to indicate the level of performance of the pupils before the intervention. The post-test results are also shown to help make a comparison between the performance of the pupils before the intervention and after the intervention. The dependent $t$-test was then used to find out whether there is any significant difference between the pre-test scores and the post-test scores. Table 1 presents the pre-test scores of the pupils out of ten points.

\begin{tabular}{|c|c|c|c|c|}
\hline Score & Number & & Percent & C \% \\
\hline 0 & 7 & & 23.3 & 23.3 \\
\hline 1 & 8 & & 26.7 & 50.0 \\
\hline 2 & 5 & & 16.7 & 66.7 \\
\hline 3 & 4 & & 13.3 & 80 \\
\hline 4 & 4 & & 13.3 & 93.3 \\
\hline 5 & 2 & & 6.7 & 100 \\
\hline Mean & & 1.87 & & \\
\hline Total & 30 & & 100 & \\
\hline \multicolumn{5}{|c|}{ Table 1: Results of Pre-test } \\
\hline
\end{tabular}

From Table 1, it can be seen that, seven pupils representing $23.3 \%$ of the pupils scored zero before the intervention. This suggests that, these students had little or no appropriate skill in reading comprehension. They could not respond appropriately to the tasks that were assigned to them. Also, no student scored any mark beyond 5. This implies that, all the pupils have had one problem or another as far as reading comprehension is concerned. This necessitated the intervention administered by the researcher. The results from Table 1 also show that the pupils recorded a mean score of 1.87 out of 10 . Since 1.87 is less than the average score of 5 , it means that the pupils performed below average before the intervention. Based on the below average level of performance of the pupils in the pre-intervention stage, an intervention, the syllabic method of teaching, was put in place. After the intervention, a post- test was conducted to ascertain whether the intervention had a positive impact on the ability of the pupils to read or not. Table 2 presents the results of the posttest.

\begin{tabular}{|c|c|l|c|c|}
\hline Score & Number & & Percent & C \% \\
\hline 4 & 2 & & 6.7 & 6.7 \\
\hline 5 & 4 & & 13.3 & 20.0 \\
\hline 6 & 5 & & 16.7 & 36.7 \\
\hline 7 & 8 & & 26.7 & 63.3 \\
\hline 8 & 6 & & 20.0 & 83.3 \\
\hline 9 & 5 & & 16.7 & 100 \\
\hline Mean & & 6.90 & & \\
\hline Total & 30 & & 100 & \\
\hline
\end{tabular}

Table 2: Results of Post-test

From Table 2, no pupil scored below four marks during the post-test whereas in the pre-test, as many as $80 \%$ of the pupils scored below four marks. This means that, the intervention helped to improve the skills of the pupils in reading. Again, whereas during the pre-test, no student scored above five, as many as 26 pupils representing $80.0 \%$ scored above five during the post-test. Also, the mean score of the pupils during the pre-test was 1.87 as compared to the mean score of 6.50 for the post-test. This shows that, there was an improvement in the performance of the pupils after the use of the syllabic method. As to whether this improvement is statistically significant, the mean scores were subjected to a dependent t-test. Table 3 presents the results of the dependent t-test.

\begin{tabular}{|c|c|c|c|c|c|}
\hline Number & d.f & t-test & Mean diff & Sig Value & Remarks \\
\hline 30 & 29 & 44.831 & 5.03 & 0.000 & Significant \\
\hline
\end{tabular}

Results from Table 3 reveal a significant value of 0.000 and at value of 44.831 at 29 degree of freedom. Since the significant value is less than the p-value of 0.05 , it can be said that, the difference is statistically significant. In summary, at $95 \%$ confidence level, there is a statistically significant difference between the performance of pupils during the pre-test and the post-test. This means that the syllabic method is an effective teaching and learning method that can be used to improve pupils' reading skills. This is in line with the findings of Adam (2016) who asserted that the syllabic method enables pupils develop word-attack skills and also helps pupils to read words on their own.

- Research Question 2: What are the challenges that teachers encounter in the use of the syllabic method in teaching reading?

This question was asked to bring to light the challenges that teachers faced in using the syllabic method of teaching reading. From the interview, it was found that one of the main challenges that teachers faced is inadequate knowledge about the syllabic method. One teacher said 
'What is this syllabic method all about?'

This suggests that the teacher like others do not have adequate knowledge about the syllabic method of teaching.

Another participant intimated that

'My class is large as you can see. I don't think I can use this method. If the class were to be few like twenty yes, I can use'.

This means that large class size is also a challenge to the use of the syllabic method. This finding is in line with the findings of Iaquinta (2006) who reported that large class size is a major problem in most schools and this has repercussions on the use of the syllabic method.

Again, the participant further added that

'I don't have materials including books and word cards to enable meuse this method of teaching. Until such a time that I get these materials, I will always read aloud for the students to repeat after me'.

A third participant also added that

'There are so many syllabi to be taught which makes teaching and learning boring'.

In summary, the challenges that teachers face with regard to the use of the syllabic method relates to the competencies of the teacher, unfavourable environment, inadequate materials and the convoluted structure of the English Language.

- $\quad$ Research Question 3: What are the suggested solutions to the challenges that teachers face in using the syllabic method of teaching?

This question was posed to elicit from the participants how the challenges could be resolved. A participant indicated that

'I think we need more education on the syllabic method of teaching because most of us don't know how to use it'.

This means that refresher courses and workshops should be organized for primary school teachers on the various methods of teaching especially, the syllabic method.Another participant also suggested that

'.......... the required materials needed for teaching English such as word cards and flash cards should be provided to help the students'.

In effect, organizing refresher courses and provision of relevant materials will ensure the effective use of the syllabic method of teaching.

\section{Conclusion}

The challenges that teachers face with regard to the use of the syllabic methodare multifaceted. These hindrances include the incompetence of the teacher, unfavorable environment, inadequate materials and the complex structure of the English Language. Notwithstanding, the syllabic method is an effective instructional strategy that can be used to improve the reading skills of pupils. Its use can be made more effective in the classroom if workshops are organized for teachers to sharpen their skills and competencesas well as the provision of relevant teaching and learning materials for instruction.

\section{Recommendations}

Based on the findings and conclusions drawn from the study, the following are recommended

- Management at the Municipal Education office should organize in-service training and workshops for teachers on the use of the syllabic method. This would enable teachers to improve their competences and skills in the use of the syllabic method.

- Teachers should also incorporate the syllabic method of teaching with other methods of teaching reading in order to help pupils overcome their reading difficulties.

\section{References}

i. Adam, A. (2016).Improving the English reading ability of Primary Four (4) pupils of Evangelical Presbyterian College of Education Primary School in Bimbilla. An unpublished Master's Thesis submitted to the Department of Educational Foundations, Faculty of Education, University for Development Studies, Tamale, Ghana.

ii. Ankrah, G. K., Nyanta, D. and Opoku, K. (2017). Using phonic method to improve poor reading ability of pupils at Techiman Senior High School form one.European Journal of Education Studies, 3(6), 759-784

iii. Aukerman, R. C. (1984). Approaches to beginning reading. (2nd Edition). New York: John Wiley and Sons.

iv. Beryl, L. and Marcelle, P. (2004) English Handbook \&Study Guide. Heineman Educational Publishers, Jordan Hill, Oxford 0X2 8EJ.

v. Birch, B. (2002). English language reading: Getting to the bottom. Mahwah, NJ: Erlbaum.

vi. Charlotte, S.H. (1967), Planning the Literature Program for the Elementary School. In I.M. Tiedt and S.W. Tiedt (eds). Reading on Contemporary English in the Elementary School. New Jersey PRENTICE-HALL Inc. Englewood Cliffs, P.205-213.

vii. Creswell, J. W. (2012). Research design: Qualitative and quantitative approaches. Thousand Oaks, CA: Sage.

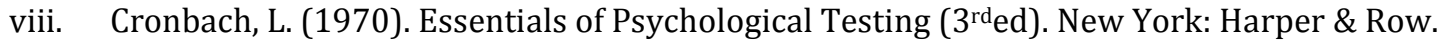

ix. Dick, B. (2002). 'Postgraduate programs using action research', The Learning Organization, 9(3/4), 159-170.

X. Duff, F. J. Hayiou-Thomas, M. E. \&Hulme, C. (2011). Evaluating the effectiveness of a phonically based reading intervention for struggling readers with varying reading profiles. Reading and writing: an interdisciplinary journal, 25(3) 621-627

xi. Durell, D.D. (1956). Improving Reading Institution. New York: Harcourt Bruce. 
xii. Heidi, B. (1998). Reading in the beginning and intermediate college foreign language Class. In Grace Stovall Burkart (Eds). Modules for the professional preparation of teaching assistants in foreign languages. Washington, D.C: Centre for Applied Linguistics.

xiii. Iaquinta, A. (2006). Guided Reading: A research-Based Response to the Challenges of Early Reading Instruction. Early childhood education Journal, 33(6), 1-9

xiv. Leherr, K (2009). National Literacy Acceleration Program (NALAP): Baseline Assessment. Accra: USAID.

xv. Lerner, J. (2006), Learning Disabilities and Related Disorder: Characteristics and Teaching Strategies (10th ed.) New York: Houghto Mifflin.

xvi. Mills, G. E. (2011). Action research: A guide for the teacher researcher (4th ed.). Boston: Pearson.

xvii. Nancy, A. and Keith, A. (2009). The Minimum Core for Language and Literacy: Knowledge, Understanding and Personal Skills. 33 Southernhay East Exeter: Learning Matters Ltd.

xviii. Rapoport, R. N. (1970). 'Three dilemmas in action research: With special reference to the Tavistock experience', Human Relations, 23(6), 499-513.

xix. Richards, T. C., \& T. S. Rodgers (1986). Approaches and Methods in Language Teaching. Cambridge: Cambridge University Press.

xx. Ruddell, R. and Singer, H. (1994). Theoretical models and processes of reading. Newark DE: International Reading Association.

xxi. SIL International (1999). What is a reading approach? Retrieved from http://www.sil.org/lingualinks/literacy/referencematerials/glossaryofliteracyterms/whatisareadingapproac h.htm.

xxii. Snow, C. E., Burns, M. S. and Griffins, P. (1998). Preventing reading difficulties in young children. Washington, D.C.: National Academy Press.

xxiii. Wendy, A.S. and Lisbeth, H.Y. (1990). Teaching English to Children. Longman Inc., New York, USA. 